ARTICLE

Received 17 Jul 2014 | Accepted 23 Mar 2015 | Published 18 May $2015 \quad$ DOl: 10.1038/ncomms7998

\title{
Volcano seismicity and ground deformation unveil the gravity-driven magma discharge dynamics of a volcanic eruption
}

\author{
Maurizio Ripepe ${ }^{1}$, Dario Delle Donne ${ }^{1, \dagger}$, Riccardo Genco ${ }^{1}$, Giuseppe Maggio ${ }^{1}$, Marco Pistolesi ${ }^{1}$, \\ Emanuele Marchetti', Giorgio Lacanna ${ }^{1}$, Giacomo Ulivieri ${ }^{1} \&$ Pasquale Poggi ${ }^{2}$
}

Effusive eruptions are explained as the mechanism by which volcanoes restore the equilibrium perturbed by magma rising in a chamber deep in the crust. Seismic, ground deformation and topographic measurements are compared with effusion rate during the 2007 Stromboli eruption, drawing an eruptive scenario that shifts our attention from the interior of the crust to the surface. The eruption is modelled as a gravity-driven drainage of magma stored in the volcanic edifice with a minor contribution of magma supplied at a steady rate from a deep reservoir. Here we show that the discharge rate can be predicted by the contraction of the volcano edifice and that the very-long-period seismicity migrates downwards, tracking the residual volume of magma in the shallow reservoir. Gravity-driven magma discharge dynamics explain the initially high discharge rates observed during eruptive crises and greatly influence our ability to predict the evolution of effusive eruptions.

\footnotetext{
${ }^{1}$ Dipartimento di Scienze della Terra, Università di Firenze, Firenze 50121, Italy. ${ }^{2}$ Istituto Nazionale di Ottica, Consiglio Nazionale delle Ricerche, Firenze 50121 , Italy. ${ }^{\dagger}$ Present address: Dipartimento di Scienze della Terra, Università di Palermo, Palermo 90123, Italy. Correspondence and requests for materials should be addressed to M.R. (email: maurizio.ripepe@unifi.it).
} 
F irst defined as the instantaneous flow output of a vent ${ }^{1}$, the lava effusion rate is now regarded as a vital parameter for interpreting eruptive dynamics and for hazard management during volcanic crises. Most basaltic eruptions are characterized by exponential decays in the effusion rate, which are explained by the tapping of a pressurized reservoir ${ }^{2,3}$. The origin of the rapid lava discharge rate in the initial phase of the eruption, as well as the overpressure of the magmatic reservoir, is unclear, and this has a strong impact on our ability to reliably assess the associated risks.

Similar to eruptions at other basaltic volcanoes, the effusion rate of the February 2007 eruption of the Stromboli volcano (Aeolian Archipelago, Southern Italy) exhibits a rapid exponential decay characterized by an initial discharge rate of $23 \mathrm{~m}^{3} \mathrm{~s}^{-1}$ that rapidly dropped to $\sim 3 \mathrm{~m}^{3} \mathrm{~s}^{-1}$ within a few days ${ }^{4-7}$. Although the measurement of effusion rates is a challenge at the best of times, in the case of the 2007 Stromboli eruption, the rate was measured using the thermal data from two different satellites (Advanced Very High Resolution Radiometer (AVHRR) and Moderate Resolution Imaging Spectroradiometer (MODIS)), which were compared with ground-based thermal ${ }^{8}$ and topographic laser scanner measurements ${ }^{6}$.

One week after the eruption onset ( 7 March) the crater terrace collapsed, forming a $\sim 300$-m-long by $\sim 140$-m-wide caldera ${ }^{5,6}$ with major consequences for the stability of this potentially tsunamogenic structure ${ }^{9}$. High magma effusion rates can in fact trigger instability in the steep slope flanks of volcanic edifices ${ }^{10,11}$. On 15 March, as a possible final consequence of the effusive dynamics, a violent 'paroxysmal' explosion several orders of magnitude larger than normal Strombolian activity occurred and metre-sized bombs hit the two nearby villages $\sim 2 \mathrm{~km}$ from the craters $^{12}$. The eruption finally ceased on 2 April 2007 after erupting $8.2 \pm 1.5 \times 10^{6} \mathrm{~m}^{3}$ of dense rock equivalent (DRE) lava in 34 days ${ }^{6,8}$.

This eruption offered a unique opportunity to analyse the evolution of the effusive regime and to understand the link between geophysical parameters and the effusive dynamics. We show that the effusion rate can be measured by ground deformation, which coincides with the contraction of the volcano, and that the magma level within the conduit can be successfully tracked by the lowering of the very-long-period (VLP) seismicity during the effusive event, presenting a useful method for monitoring the real-time evolution of effusive volcanic eruptions.

\section{Results}

Migration of the VLP seismic source. This eruption was monitored by a large number of geophysical and geochemical sensors, including a broad-band seismic station and two tiltmeters (stations STR, LSC and OHO, respectively, in Fig. 1a). Volcanic activity was also recorded with a thermal camera (station ROC in Fig. 1a) located on the northeast flank of the volcano at an elevation of $650 \mathrm{~m}$ a.s.l. (above sea level) and at a distance of $\sim 500 \mathrm{~m}$ from the active vents.

The transition from the persistent Strombolian explosive activity to the effusive regime began on 27 February 2007 (ref. 13) when a well-supplied lava effusion began to flow from a lateral vent at $400 \mathrm{~m}$ a.s.l. within the Sciara del Fuoco slope and explosive activity at the summit craters suddenly ceased (Fig. 1). However, the VLP seismicity commonly associated with the explosive activity was uninterrupted ${ }^{14}$. Despite the transition to effusive activity and the absence of Strombolian explosions, the VLP volcanic seismicity remained intense $\mathrm{e}^{13,14}$.

The location of VLP seismicity in Stromboli is in general considered to be stable at $\sim 500 \mathrm{~m}$ a.s.l. ${ }^{15}$, which corresponds to a depth of $220-300 \mathrm{~m}$ below the active craters. This depth represents the position of the centroid of the seismic moment inversion ${ }^{15}$ and is interpreted as a change in conduit geometry (a dyke merging into a pipe or a change in the dyke slope), which is responsible for the sudden expansion of the gas slug ${ }^{15,16}$ that eventually explodes upon reaching the magma surface. Here, we present evidence that forces us to change this scenario of stability and that opens questions on the origins of this seismic signal.

The relative changes of source location can be tracked by calculating the orientation of the ground displacement particle motion vector that represents the propagation path of the longitudinal P-wave component of the VLP events ${ }^{17}$. Due to the uncertainty in seismic velocity structure and in the curvature of the $\mathrm{P}$-wave path, the inclination in the displacement vector cannot directly deduce absolute changes in the VLP source position, but can be considered to be an efficient tracer of the relative movement of the source.

The displacement vectors of $\sim 300,000$ seismic VLPs recorded at STR (Fig. 1a) between January 2006 and January 2008 (Fig. 2a) exhibit a stable inclination of within $\sim-4^{\circ}$ below the station until the beginning of February 2007. At the onset of the eruption, the inclination of the vector changes and progressively moves downwards, reaching $\sim-13^{\circ}$ at the end of the eruption on 2 April (Fig. 2a). At this time, the inclination of the ground displacement vector begins to move upward again, reaching a stable position of $\sim-9^{\circ}$ on 1 May (Fig. 2a).

This change in VLP source position is also confirmed by the analysis of 11 broad-band seismic stations ${ }^{14}$ and was also observed during the 2003 eruption ${ }^{17}$. The drift of the VLP seismicity appears to follow the drainage of the magma during the effusive eruption. These observations are difficult to reconcile with the previous image of a stable VLP source in the central conduit ${ }^{15}$ and cannot be explained with effusive dynamics solely sustained by the magma supply rate from depth.

Volume of lava discharged and VLP source migration. The effusion rate $Q(t)$ can be converted into the magma volume resident in the reservoir, $V_{\mathrm{R}}(t)=V_{0}-\int_{t^{\prime}=0}^{t} Q\left(t^{\prime}\right) \mathrm{d} t$, where $V_{0}=8.2 \pm 1.5 \times 10^{6} \mathrm{~m}^{3}$ is the total erupted volume of DRE magma (Supplementary Table 1). The residual magma volume $V_{\mathrm{R}}$ represents the way the reservoir progressively empties during the eruption. The measured volume of magma $V_{\mathrm{R}}(t)$ yet to be discharged correlates well $\left(R^{2}=0.93\right)$ with the migration trend of the VLP displacement vector (Fig. 3). This linear correlation (Fig. 3 inset) provides remarkable evidence for a link between the volume of magma discharged and the vertical position of the VLP seismicity, indicating that the effusive volume decreases linearly with depth. This provides a strong constraint on the geometry and position of the reservoir. The reservoir can thus be represented by a shallow cylindrical plumbing system immediately above the effusive vent, with the same area as the crater terrace, $A_{0} \sim 3.0 \pm 0.2 \times 10^{4} \mathrm{~m}^{2}$ (equivalent to an ellipse $\sim 300 \mathrm{~m}$ long by $\sim 140 \mathrm{~m}$ wide, Fig. 1c). In this case, the residual volume, $V_{\mathrm{R}}(t)$, can be converted to changes in the magma level in the reservoir:

$$
h(t)=4 \frac{V_{\mathrm{R}}(t)(1+\phi)}{A_{0}}
$$

where $\phi$ is the magma vesicularity ranging between 0.14 and 0.45 (ref. 18). With this geometry, we calculate that the change in the residual magma volume reflects a total lowering of the magma level in the conduit of 286 and 363 m below the surface, within the considered magma vesicularity range. Both cases indicate that the magma level before the eruption was very shallow, between 686 and $763 \mathrm{~m}$ a.s.l.

The VLP source location thus tracks the position of the magma level in the conduit during the effusive eruption, which has 

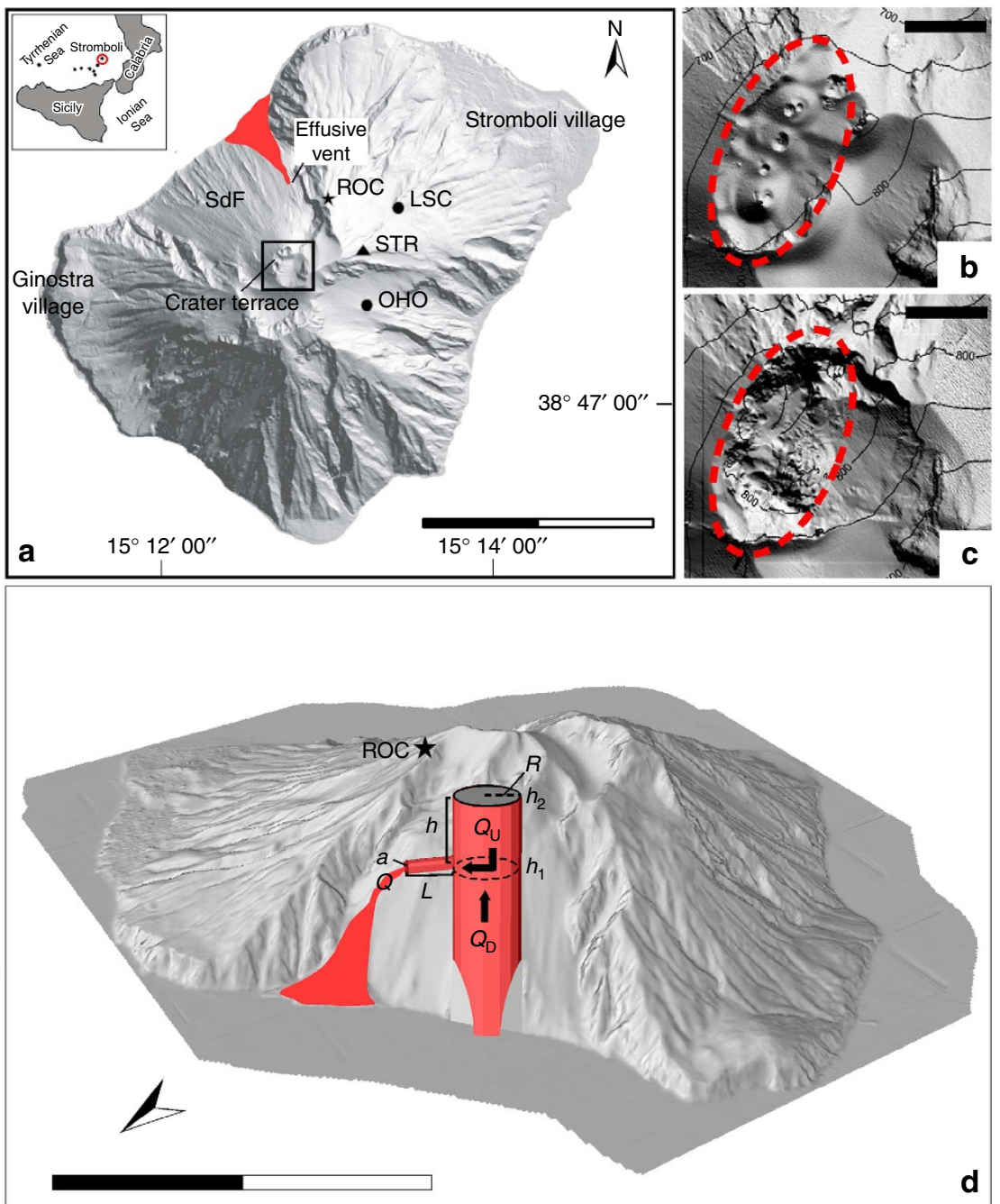

Figure 1 | (a) Shaded relief map of Stromboli with the main lava flow during the 2007 eruption and position of the lateral effusive vent at $400 \mathrm{~m}$ elevation in the Sciara del Fuoco (SdF). Scale bar, $2 \mathrm{~km}$. Location of the geophysical network operating during the 2007 eruption: the star (ROC) indicates the position of the thermal camera (uncooled microbolometer FLIR-A20), the triangle (STR) represents the position of the broad-band seismic station (CMG-40T, $800 \mathrm{Vm}^{-1} \mathrm{~s}^{-1}$, eigenperiod $30 \mathrm{~s}$ ), and the circles (LSC and OHO) mark the two tiltmeters (Pinnacle 5000T sampled at $1 \mathrm{~Hz}$ and with a sensitivity of $1 \mathrm{nrad}$ ). The black square delimits the area represented in $\mathbf{b}$ and $\mathbf{c}$. (b) Close-up of the crater area before the 7-9 March 2007 crater terrace collapse. (c) Crater area after the collapse (red dashed line). Scale bars, $100 \mathrm{~m}(\mathbf{b}, \mathbf{c})$. (d) The volcano seen from the north, with a sketch of the shallow reservoir with the parameters used to calculate the discharge model. Scale bar, $2 \mathrm{~km}$. Qu represents the supply rate from the reservoir above the lateral vent, $Q_{D}\left(0.7 \mathrm{~m}^{3} \mathrm{~s}^{-1}\right)$ is the steady magma supply rate from depth, $Q$ is the effusive rate from the lateral vent, $a(1.5 \mathrm{~m})$ is the radius of the effusive channel, $L(98-154 \mathrm{~m})$ is the length of the channel, $h$ is the magma level above the effusive vent $(286-363 \mathrm{~m})$ and $R(95 \pm 5 \mathrm{~m})$ is the radius of the reservoir within the considered vesicularity range of 0.14 and 0.45 . $\mathbf{b}$ and $\mathbf{c}$ are redrawn after ${ }^{6}$.

significant consequences for our understanding of the VLP source mechanisms and for volcano monitoring in general.

When the eruption ceased on 2 April, the position of the VLP seismicity moved upwards, reaching a stable dip of $-9^{\circ}$. This inclination is $\sim 5^{\circ}$ deeper than before the eruption (Fig. 2a), suggesting that the magma level only partially recovered its initial position. This observation is consistent with the lower elevation of the craters after the eruption (Fig. 1b,c), due to the $\sim 65 \mathrm{~m}$ of subsidence in the terrace floor ${ }^{6}$. The topographic elevation of the crater floor limits the position of the magma level and appears to limit the level and the depth of the VLP seismicity within the conduit, as we now discuss.

Tracking crater growth and VLP seismicity. Using thermal image analysis, we tracked the evolution of the crater terrace from
January 2006 until January 2013. The deposition of hot scoria ejected by the persistent explosive activity falling on the crater rim provided a strong thermal contrast between the ground and the cold background sky, allowing the tracking of the crater terrace's elevation changes through time.

The thermal image analysis shows that the position of the craters remained at a stable elevation of $\sim 760 \mathrm{~m}$ a.s.l. until the onset of the eruption (Fig. 2b). During the 7-9 March collapse, the crater terrace dropped far below the field of view of the thermal camera. After 2 April 2007, at the eruption's end, the thermal camera again detected the growth of the crater terrace as a consequence of the resumed explosive activity at the vent. Remarkably, changes in the topographic elevation of the craters are associated with the variations in the VLP seismicity position (Fig. 2b), confirming the link between the VLP seismicity and the magma level within the conduit. 
a
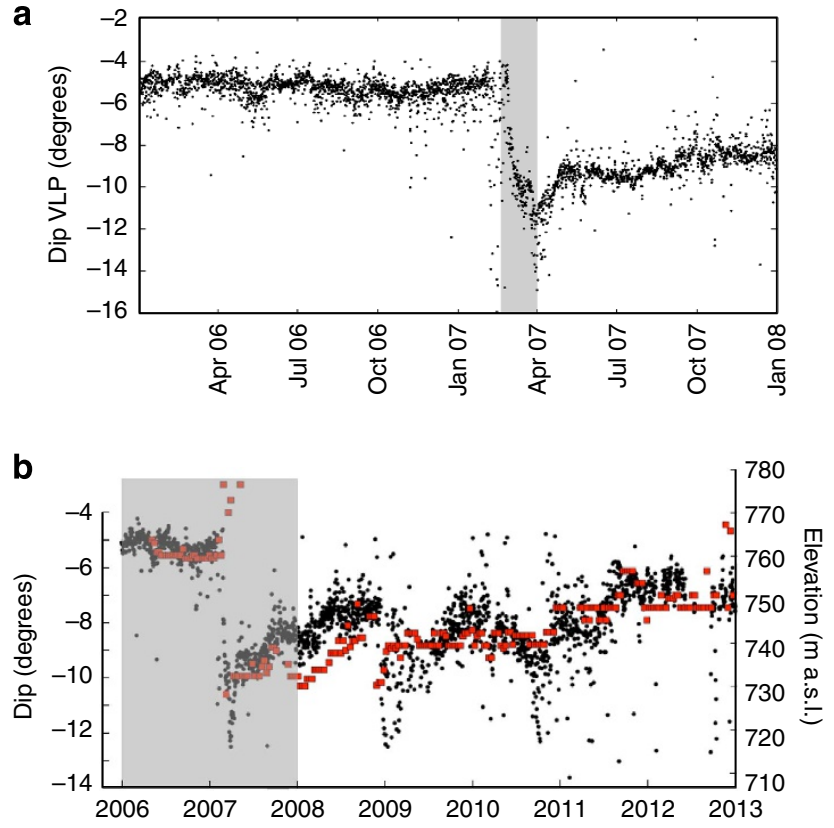

Figure 2 | (a) Dip of the ground displacement vector calculated for 280,548 VLP seismic events recorded at STR (see Fig. 1a) between January 2006 and January 2008. Dip is measured from the horizontal plane defined by the station elevation and remained almost stable at approximately $-5^{\circ}$ until the onset of the eruption. On 27 February 2007, the VLP source shifts progressively deeper to $-13^{\circ}$ until 2 April 2007, when the VLP source shifts back towards the surface. Position becomes stable at $-9^{\circ}$ on 1 May 2007, but the pre-eruptive conditions have not yet been reached. The grey area represents the duration of the 2007 eruptive phase. (b) Seven years of displacement vector inclinations (black dots) are compared with the elevation of the crater rim (red squares), as measured by the thermal camera at ROC. The correlation suggests that the position of the seismic source is constrained by the topography and reflects changes in the magma level in the shallow conduits. In 2013, 6 years after the eruption, the $2.1 \times 10^{6}-\mathrm{m}^{3}$ caldera (Fig. 1c) has not been totally filled. The grey area represents the time window shown in $\mathbf{a}$.

In 2013, 6 years after the eruption, the pre-eruptive elevation of the crater terrace has still not entirely recovered. The elevation of the explosive vents is at $\sim 750 \mathrm{~m}$ a.s.l., $\sim 10 \mathrm{~m}$ lower than the level prior to 2007, and the VLP seismicity has not totally returned to the $\sim 5^{\circ}$ pre-eruptive inclination (Fig. 2b). During these 6 years, the large $\sim 2.1 \times 10^{6}-\mathrm{m}^{3}$ caldera-like structure ${ }^{6}$ has been partially filled with scoria and bombs by explosive activity, with a mean magma output rate of $\sim 0.01 \mathrm{~m}^{3} \mathrm{~s}^{-1}$. This is consistent with the characteristic rate of Strombolian activity characterized by 10 explosions per hour, each $\sim 3.6 \mathrm{~m}^{3}$ in size $\mathrm{s}^{13,19}$.

Modelling the gravity-driven lava discharge rate. The effusion rate, $Q_{\mathrm{U}}(t)=\pi a^{2} u(t)$, decays in time depending on the exit velocity, $u(t)$, of the lava flow from the vent with radius $a(1.5 \mathrm{~m}$ in our case $\left.^{20}\right)$. Modelling the effusion rate means modelling changes in the exit velocity with time. The exponential decay of the effusion rate can be modelled by assuming that gravity is draining magma out of the reservoir through a dyke-like channel of length $L$ with exit velocity controlled by Poiseuille flow in the channel ${ }^{2}$ :

$$
u(t)=\frac{a^{2}}{4 \eta L} \Delta P(t)
$$

where $\eta$ is the magma viscosity of $10^{4} \mathrm{Pas}^{21}$. Because the magma was near the surface before the eruption ${ }^{4,9}$, we use the relationship

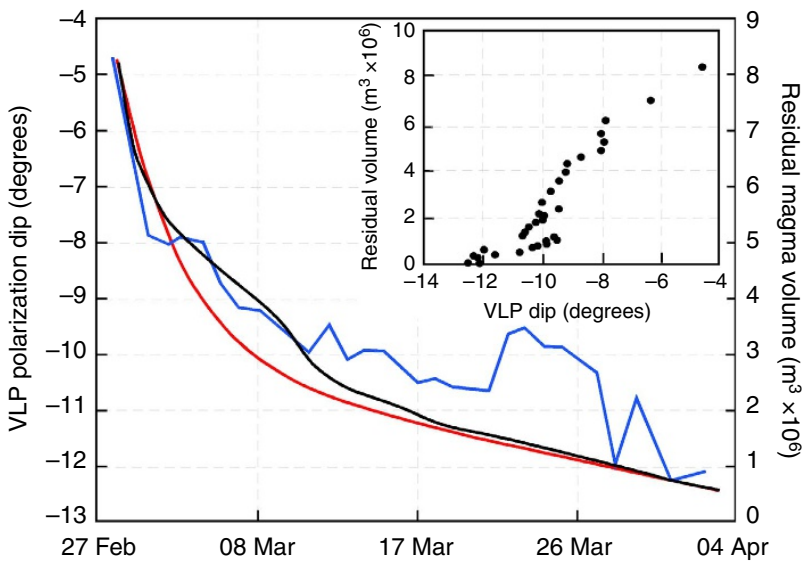

Figure 3 | The migration of the VLP inclination vector (blue line) measured during the eruption (grey band in Fig. $2 a$ ) is compared with the residual magma volume in the upper cylindrical reservoir (black line) by assuming the measured effusion rate and with the discharge model (equation (1)) controlled by the drainage of magma stored above the vent (red line). The inset shows the remarkably good $\left(R^{2}=0.93\right)$ correlation between the level of magma $h(t)$ in the reservoir and the seismic source dip.

$\Delta P(t)=P_{\mathrm{h}}(t)-P_{\mathrm{atm}}$ to calculate the pressure difference between the magmastatic pressure of the reservoir, $P_{\mathrm{h}}(t)=\rho g h(t)(1-\phi)$, and the atmospheric pressure at the vent, $P_{\mathrm{atm}}=10^{5} \mathrm{~Pa}$, where $h(t)$ is the gradual reduction of the magma level above the effusive vent (equation (1)) and $\rho=2,950 \mathrm{~kg} \mathrm{~m}^{-3}$ is the DRE magma density $^{22}$ (Supplementary Table 1 ).

The modelled extrusion rate, $Q_{U}(t)$, exhibits the best fit with the observed extrusion rate (Fig. 4) and with the volumetric discharge associated with the migration of the VLP seismicity (Fig. 3) for a channel length $L$, ranging between 98 and $154 \mathrm{~m}$ in the assumed vesicularity range (Fig. 1d).

However, in both cases, the predicted effusion rate quickly decays to zero (Fig. 4, dashed red line) and the model is not able to fully reproduce a long-lasting effusive eruption. The model indicates that magma supplied from depth should be considered a damping factor in the drainage dynamics of the shallow reservoir and that this supply provides an important contribution to sustaining the eruption.

The extrusion rate $Q(t)=Q_{\mathrm{U}}(t)+Q_{\mathrm{D}}$ can be considered the result of the magma drainage $Q_{\mathrm{U}}(t)$ from the reservoir above the effusive vent and the magma supply rate $Q_{D}$ from depth. The total extrusion rate is then successfully modelled (Fig. 4) only when a steady contribution of $Q_{D}=0.7 \mathrm{~m}^{3} \mathrm{~s}^{-1}$ of magma supplied from depth is considered, in addition to the gravitydriven (equation (1)) discharge dynamics of the shallow reservoir $Q_{\mathrm{U}}(t)$ below the crater terrace.

This is in agreement with gas flux measurements ${ }^{23,24}$. The $\mathrm{SO}_{2}$ flux, in fact, increased from an average of $220 \mathrm{t}$ per day before the eruption to $610 \mathrm{t}$ per day during the eruption ${ }^{23}$, a sign that magma was supplied from depth at a rate $\sim 2.7$ times higher during the eruption than before. Considering the characteristic mean pre-eruptive magma supply rate of $0.28 \mathrm{~m}^{3} \mathrm{~s}^{-1}$ (ref. 23), the increase of $\mathrm{SO}_{2}$ flux is consistent with a deep magma supply rate of $\sim 0.75 \mathrm{~m}^{3} \mathrm{~s}^{-1}$ during the eruption, which is similar to the rate predicted by the modelling.

Modelling ground deformation by effusion rate. The rapid decay of the extrusion rate correlates well with the ground deformation (Fig. 4) recorded by the tiltmeters located at 


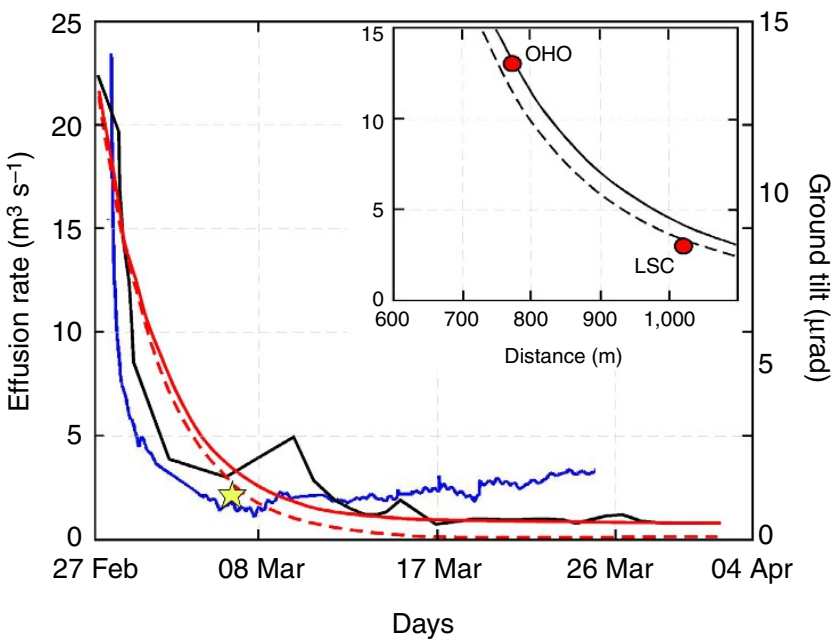

Figure 4 | Comparison between the ground tilt at the OHO station (blue), the observed effusion rate (black) and modelled discharge (red). The model (equation (1)) assumes a steady deep magma supply rate $\left(Q_{D}\right)$ of $0.7 \mathrm{~m}^{3} \mathrm{~s}^{-1}$ and a shallow plumbing system represented by a cylindrical reservoir immediately above the effusive vent, with the same area as the crater terrace, $A_{0}=3.0 \pm 0.2 \times 10^{4} \mathrm{~m}^{2}$. When no deep magma is supplied $\left(Q_{D}=0\right.$; red dashed line), the discharge rate of the shallow reservoir goes to zero after 18 days following the eruption onset. A value of $Q_{D}=0.7 \mathrm{~m}^{3} \mathrm{~s}^{-1}$ is consistent with the $\mathrm{SO}_{2}$ flux measured during the eruption ${ }^{16}$. The yellow star indicates the change in the effusion rate measured during the eruption, which coincides with the maximum ground deflation ( $13 \mu \mathrm{rad}$ ) detected by a tiltmeter and with the collapse of the crater terrace. Inset: the ground tilt, modelled (equation (4)) as the magmastatic pressure drop of 6.7 and $4.3 \mathrm{MPa}$ and assuming a vesicularity range of 0.14 (dashed line) and 0.45 (bold line), respectively, gives the best fit with the maximum ground deflation observed at both $\mathrm{OHO}$ and LSC stations (red dots). This corresponds to the lowering of the magmatic column by $330 \pm 20 \mathrm{~m}$.

distances of $765 \mathrm{~m}$ (OHO at an elevation $570 \mathrm{~m}$ a.s.l.) and $1,015 \mathrm{~m}$ (LSC at an elevation of $520 \mathrm{~m}$ a.s.l.) from the active vents (Fig. 1a,d). The largest ground deformation, $-13 \mu \mathrm{rad}$ at $\mathrm{OHO}$ and $-2.8 \mu \mathrm{rad}$ at LSC, is reached between 7 and 9 March (Fig. 4), and it coincides with the collapse of the floor of the crater terrace.

Because the ground deformation is driven by the effusive drainage of magma, as a first approximation, we model the ground tilt $(\tau)$ as the result of the normal stress acting on the wall of the cylindrical open conduit ${ }^{25,26}$ of radius $R=95 \pm 5 \mathrm{~m}$ (which is the equivalent of the surface area of the crater terrace):

$$
\tau(t)=G \frac{R^{2}}{\mu} \Delta P(t)
$$

where $\mu$ is the rigidity, with a value of $1.3 \times 10^{9} \mathrm{~Pa}^{27}$ and $G$ is a parameter, which depends on the relative position of the conduit with respect to the stations (Supplementary Note 1). This source contracts following the pressure difference $\Delta P$ related to the effusion rate $Q(t)$ modelled as magmastatically driven Poiseuille flow $^{28}$ (equation (1)). The expected ground tilt induced by the measured effusion rate (Fig. 4) is then calculated as follows:

$$
\tau(t)=G \frac{4 \eta L R^{2}}{\pi \mu a^{4}} \Delta Q(t)
$$

where $\Delta Q(t)=Q_{0}-Q(t)$ is the change in effusion rate with time $\left(Q_{0}=23 \mathrm{~m}^{3} \mathrm{~s}^{-1}\right)$. Although the trend of the modelled tilt $\tau(t)$ obviously resembles the effusion rate $Q(t)$, the best fit with the absolute measured ground tilt at the two stations ${ }^{26}$ (OHO and
LSC) is reached for a magmastatic decompression of 6.7 and $4.3 \mathrm{MPa}$ relative to a vesicularity of 0.14 and 0.45 (ref. 18), respectively (Fig. 4 inset). We do not consider in this analytic solution the steep volcano topography; however, the ground deformation, in agreement with the gravity-driven magma discharge model, is reasonably explained by the $330 \pm 20-\mathrm{m}$ lowering of the magma in the shallow reservoir located above the effusive vent. This hypothesis provides a useful way to calculate the effusion rate during an eruption in real time. The largest contraction of the source was reached between 7 and 9 March, when $\sim 66 \%$ of the total volume stored in the shallow portion of the conduit had already been erupted, and this contraction coincided with the largest modelled magma level drop and with the collapse of the crater terrace.

\section{Discussion}

During normal explosive activity, magma flows within the conduits of the Stromboli volcano at a rate of $\sim 0.3 \mathrm{~m}^{3} \mathrm{~s}^{-1}$ (ref. 29), but the explosive mechanisms release only a small fraction of the long-term magma supply rate from depth $\left(\sim 0.01 \mathrm{~m}^{3} \mathrm{~s}^{-1}\right)$. The explosive activity does not evacuate all the magma supplied, which is thus slowly stored at shallow depth and possibly recycled within the plumbing system in which it evolves and crystallizes ${ }^{21}$. This mechanism explains why there was no clear evidence of ground inflation in the days, months and years preceding the eruption ${ }^{30,31}$.

The high gas flux measured during lava effusion ${ }^{23,24}$ indicates the increased contribution of a gas-rich, deep-seated magma, and is suggested to be responsible for the increase in magma vesicularity within the shallow reservoir ${ }^{23}$. The discharge of magma during the effusive eruption probably hampered the recycling of the degassed magma, leading to a decrease in the bulk magma density of the shallow plumbing system ${ }^{23}$. This hypothesis explains the contraction of the intermediate depth $(2-3 \mathrm{~km})$ magma reservoir observed by ground deformation measurements ${ }^{32}$.

The lava discharge mechanism is thus responsible for the gas exsolution in deeper portions of the conduit, promoting the gradual upward rise in the gas-rich magma column ${ }^{20,23}$. This process is considered to be the cause of the decompression of the deep $(7-10 \mathrm{~km})^{21,33,34}$ magma reservoir, which in turn triggered the rapid, buoyant rise of the crystal-poor, volatile-rich batch of magma during the 15 March violent 'paroxysmal' explosion ${ }^{20,23}$.

However, we show that the volume of lava discharged during the effusive eruption follows the deepening of the VLP seismicity source (Fig. 3), indicating that the magma supply rate from depth $\left(Q_{D}\right)$ was not sufficient to sustain the magma column level $\left(Q_{\mathrm{D}}<Q_{\mathrm{U}}\right)$ within the conduit. This caused the continuous drainage of magma from the shallow reservoir and the lowering of the magma column during the effusive eruption. Thus, our model indicates that the magmastatic control of the shallow reservoir exerted an active role on the deep magma dynamics during the effusive phase. This also suggests that the inferred rise of the less dense and highly vesicular magma within the magma column ${ }^{20}$ can be considered a possible consequence of the magma drainage from the shallow reservoir. The links between the position of the VLP seismicity, ground deformation and effusion rate allow us to quantify the magmastatic decompression, which ranges between 4.3 and $6.7 \mathrm{MPa}$. This offers a unique opportunity to derive the magnitude of the decompression rate from the ground tilt, which heavily influences our ability to predict the evolution of effusive eruptions at Stromboli. The magma drainage model by gravity load appears to dominate the effusive dynamics and changes our perspective from deep to shallow magma dynamics as the controlling factor for effusive eruptions. 


\section{References}

1. Walker, G. P. L. Lengths of lava flows. Phil. Trans. R. Soc. Lond. 274, 107-118 (1973).

2. Kauahikaua, J., Mangan, M., Heliker, C. \& Mattox, T. A quantitative look at the demise of a basaltic vent: the death of Kupaianaha, Kilauea Volcano, Hawai'i. Bull. Volcanol. 57, 641-648 (1996).

3. Harris, A. J. L. et al. Effusion rate trends at Etna and Krafla and their implications for eruptive mechanisms. J. Volcanol. Geotherm. Res. 102, 237-269 (2000).

4. Barberi, F., Civetta, L., Rosi, M. \& Scandone, R. Chronology of the 2007 eruption of Stromboli and the activity of the Scientific Synthesis Group. J. Volcanol. Geotherm. Res. 182, 123-130 (2009).

5. Neri, M. \& Lanzafame, G. Structural features of the 2007 Stromboli eruption. J. Volcanol. Geotherm. Res. 182, 137-144 (2009).

6. Marsella, M. et al. The evolution of the Sciara del Fuoco subaerial slope during the 2007 Stromboli eruption: relation between deformation processes and effusive activity. J. Volcanol. Geotherm. Res. 182, 201-213 (2009).

7. Spinetti, C. et al. Rapporto eruzione Stromboli 9-16 Marzo 2007, INGV, CNTLABTEL and University of Hawaii-HIGP/SOEST, Bollettino 160307 (2007).

8. Calvari, S. et al. The 2007 Stromboli eruption: event chronology and effusion rates using thermal infrared data. J. Geophys. Res. 115, B4 (2010).

9. Tinti, S. et al. Observations of physical effects from tsunamis of December 30, 2002 at Stromboli volcano, southern Italy. Bull. Volcanol. 68, 450-461 (2005).

10. Calvari, S. \& Pinkerton, H. Instabilities in the summit region of Mount Etna during the 1999 eruption. Bull. Volcanol. 63, 526-535 (2002).

11. Calvari, S., Inguaggiato, S., Puglisi, G., Ripepe, M. \& Rosi, M. The Stromboli Volcano: an Integrated Study of the 2002-2003 EruptionCalvari, S., Inguaggiato, S., Puglisi, G., Ripepe, M. \& Rosi, M. (eds 182, 399 ppGeophysical monograph series (American Geophysical Union, 2008).

12. Pistolesi, M., Delle Donne, D., Pioli, L., Rosi, M. \& Ripepe, M. The 15 March 2007 explosive crisis at Stromboli volcano, Italy: assessing physical parameters through a multidisciplinary approach. J. Geophys. Res. 116, B12 (2011).

13. Ripepe, M., Delle Donne, D., Lacanna, G., Marchetti, E. \& Ulivieri, G. The onset of the 2007 Stromboli effusive eruption recorded by an integrated geophysical network. J. Volcanol. Geotherm. Res. 182, 131-136 (2009).

14. Giudicepietro, F. et al. Changes in the VLP seismic source during the 2007 Stromboli eruption. J. Volcanol. Geotherm. Res. 182, 162-171 (2009).

15. Chouet, B. et al. Source mechanisms of explosions at Stromboli Volcano, Italy, determined from moment-tensor inversions of very-long-period data. J. Geophys. Res. 108(B1): 2019 (2003).

16. Ripepe, M., Ciliberto, S. \& Della Schiava, M. Time constraints for modeling source dynamics of volcanic explosions at Stromboli. J. Geophys. Res. 106(B5): 8713-8727 (2001).

17. Marchetti, E. \& Ripepe, M. Stability of the seismic source during effusive and explosive activity at Stromboli Volcano. Geophys. Res. Lett. 32, L03307 (2005).

18. Landi, P. et al. Magma dynamics during the 2007 Stromboli eruption (Aeolian Islands, Italy): mineralogical, geochemical and isotopic data. J. Volcanol. Geotherm. Res. 182, 255-268 (2009).

19. Harris, A. J. L., Donne, D. D., Dehn, J., Ripepe, M. \& Worden, A. K. Volcanic plume and bomb field masses from thermal infrared camera imagery. Earth Planet. Sci. Lett. 365, 77-85 (2013).

20. Calvari, S. et al. Lava effusion-a slow fuse for paroxysms at Stromboli volcano? Earth Planet. Sci. Lett. 301(1-2): 317-323 (2011).

21. Métrich, N., Bertagnini, A., Landi, P. \& Rosi, M. Crystallization driven by decompression and water loss at Stromboli volcano (Aeolian Islands, Italy). J. Petrol. 42, 1471-1490 (2001).

22. Pioli, L., Pistolesi, M. \& Rosi, M. Transient explosions at open-vent volcanoes: the case of Stromboli (Italy). Geology 42, 863-866 (2014).
23. Burton, M. R., Caltabiano, T., Mure', F., Salerno, G. \& Randazzo, D. $\mathrm{SO}_{2}$ flux from Stromboli during the 2007 eruption: results from the FLAME network and traverse meausrements. J. Volcanol. Geotherm. Res. 182, 214-220 (2009).

24. Aiuppa, A. et al. The 2007 eruption of Stromboli volcano: insights from real-time measurement of the volcanic gas plume $\mathrm{CO}_{2} / \mathrm{SO}_{2}$ ratio. J. Volcanol. Geotherm. Res. 182, 221-230 (2009).

25. Bonaccorso, A. \& Davis, P. M. Models of ground deformation from vertical volcanic conduits with application to eruptions of Mount St. Helens and Mount Etna. J. Geophys. Res. 104, 10531-10542 (1999).

26. Nishimura, T. Ground deformation caused by magma ascent in an open conduit. J. Volcanol. Geotherm. Res. 187, 178-192 (2009).

27. Genco, R. \& Ripepe, M. Inflation-deflation cycles revealed by tilt and seismic records at Stromboli volcano. Geophys. Res. Lett. 37, L12302 (2010).

28. Hreinsdóttir, S. et al. Volcanic plume height correlated with magma-pressure change at Grímsvötn Volcano, Iceland. Nat. Geosci. 7, 214-218 (2014).

29. Allard, P., Carbonnelle, J., Métrich, N., Loyer, H. \& Zettwoog, P. Sulfur output and magma degassing budget of Stromboli Volcano. Nature 368, 326-330 (1994).

30. Marchetti, E., Genco, R. \& Ripepe, M. Ground deformation and seismicity related to the propagation and drainage of the dyke feeding system during the 2007 effusive eruption at Stromboli volcano (Italy). J. Volcanol. Geotherm. Res. 182, 155-161 (2009).

31. Bonaccorso, A. et al. Insight on recent Stromboli eruption inferred from terrestrial and satellite ground deformation measurements. J. Volcanol. Geotherm. Res. 182, 172-181 (2009).

32. Bonaccorso, A. et al. Stromboli 2007 eruption: deflation modeling to infer shallow-intermediate plumbing system. Geophys. Res. Lett. 35, L06311 (2008)

33. Bertagnini, A., Métrich, N., Landi, P. \& Rosi, M. Stromboli volcano (Aeolian Archipelago, Italy): an open window on the deep-feeding system of a steady state basaltic volcano. J. Geophys. Res. 108, 23-36 (2003).

34. Francalanci, L., Tommasini, S. \& Conticelli, S. The volcanic activity of Stromboli in the 1906 - 1998 AD period: mineralogical, geochemical and isotope data relevant to the understanding of the plumbing system. J. Volcanol. Geotherm. Res. 131, 179-211 (2004).

\section{Acknowledgements}

This work was supported by the Italian Civil Protection in the framework of the DEVNET project.

\section{Author contributions}

M.R. developed the model and wrote the manuscript. D.D.D. analysed the therma images to calculate topographic changes of the craters. R.G. processed the ground tilt. G.M., G.U. and G.L. analysed the seismic VLP data. P.P. supervised all the data analysis M.P. and E.M. contributed to the writing of the manuscript and to developing the conceptual model.

\section{Additional information}

Supplementary Information accompanies this paper at http://www.nature.com/ naturecommunications

Competing financial interests: The authors declare no competing financial interests.

Reprints and permission information is available online at http://npg.nature.com/ reprintsandpermissions/

How to cite this article: Ripepe, M. et al. Volcano seismicity and ground deformation unveil the gravity-driven magma discharge dynamics of a volcanic eruption. Nat. Commun. 6:6998 doi: 10.1038/ncomms7998 (2015). 